\title{
Cathodic Corrosion of a Bulk Wire to Nonaggregated Functional Nanocrystals and Nanoalloys
}

\author{
Jicheng Feng, ${ }^{*},, \perp \odot$ Dong Chen, ${ }^{\S, \perp}$ Ahmad S. Sediq, ${ }^{\ddagger}$ Stefan Romeijn, ${ }^{\ddagger}$ Frans D. Tichelaar, ${ }^{\|}$Wim Jiskoot, ${ }^{\ddagger}$ \\ Jun Yang, ${ }^{*, 8}$ and Marc T. M. Koper*, ${ }^{\dagger}$ ○्( \\ ${ }^{\dagger}$ Catalysis and Surface Chemistry, Leiden Institute of Chemistry and ${ }^{\ddagger}$ Division of BioTherapeutics, Leiden Academic Center for Drug \\ Research, Leiden University, 2300 RA Leiden, The Netherlands \\ ${ }^{\S}$ State Key Laboratory of Multiphase Complex Systems, Institute of Process Engineering, Chinese Academy of Sciences, 100190 \\ Beijing, China \\ "Kavli Institute of NanoScience, Delft University of Technology, Lorentzweg 1, 2628 CJ Delft, The Netherlands
}

\section{Supporting Information}

ABSTRACT: A key enabling step in leveraging the properties of nanoparticles (NPs) is to explore new, simple, controllable, and scalable nanotechnologies for their syntheses. Among "wet" methods, cathodic corrosion has been used to synthesize catalytic aggregates with some control over their size and preferential faceting. Here, we report on a modification of the cathodic corrosion method for producing a range of nonaggregated nanocrystals $(\mathrm{Pt}, \mathrm{Pd}, \mathrm{Au}, \mathrm{Ag}, \mathrm{Cu}, \mathrm{Rh}, \mathrm{Ir}$, and $\mathrm{Ni}$ ) and nanoalloys $\left(\mathrm{Pt}_{50} \mathrm{Au}_{50}, \mathrm{Pd}_{50} \mathrm{Au}_{50}\right.$, and $\left.\mathrm{Ag}_{x} \mathrm{Au}_{100-x}\right)$ with potential for scaling up the production rate. The method employs poly(vinylpyrrolidone) (PVP) as a stabilizer in an electrolyte solution containing nonreducible cations $\left(\mathrm{Na}^{+}, \mathrm{Ca}^{2+}\right)$, and cathodic corrosion of the corresponding wires takes place in the electrolyte under ultrasonication. The ultrasonication not only promotes particle-PVP interactions (enhancing NP dispersion and diluting locally high NP concentration) but also increases the production rate by a factor of ca. 5 . Further increase in the production rate can be achieved through parallelization of

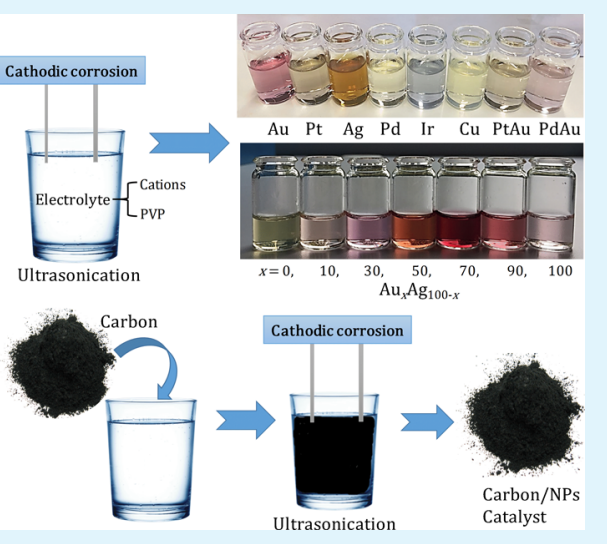
electrodes to construct comb electrodes. With respect to applications, carbonsupported Pt NPs prepared by the new method exhibit catalytic activity and durability for methanol oxidation comparable or better than the commercial benchmark catalyst. A variety of $\operatorname{Ag}_{x} A_{100-x}$ nanoalloys are characterized by ultraviolet-visible absorption spectroscopy and high-resolution transmission electron microscopy. The protocol for NP synthesis by cathodic corrosion should be a step toward its further use in academic research as well as in its practical upscaling.

KEYWORDS: cathodic corrosion, alloy nanoparticles, comb electrodes, methanol oxidation reaction, electrocatalysis, optical properties

\section{INTRODUCTION}

Recent breakthroughs in nanotechnology have been made by creating multifunctional nanoparticles (NPs) precisely engineered in size, shape, and composition. ${ }^{1-5}$ Enormous efforts have been invested in demonstrating the relevant properties of such NPs in myriad fields. ${ }^{6-9}$ However, many NP synthesis methods are confined to the laboratory scale. Adding interest to industrial market lies in elevating NP production through developing scalable methodologies. ${ }^{10-13}$

Existing technologies for producing nanomaterials can be divided into "dry" and "wet" methods. For example, aerosolbased dry methods are continuous processes, some of which lead to high-purity NPs due to the absence of liquid precursors. ${ }^{14}$ However, the high-purity NPs need protection (their surface atoms are sensitive to trace amounts of reactive gas molecules), ${ }^{13}$ thereby hampering practical utilization. Another limiting factor that militates against efficiently capturing the aerosol particles is the fast kinetics of particle formation resulting in rapid agglomeration. On the other hand, wet chemistry routes often require tedious multistep operations, expensive, and/or toxic precursors, and may eventually have poor yields, thus constraining the scalability and sometimes causing environmental detriment. ${ }^{15-19}$ However, they have the capability to control the colloidal growth for obtaining diverse nanoparticulate morphologies. ${ }^{20-22}$ Combining morphological and compositional control presents unique opportunities to optimize the properties of NPs. Still, achieving independent control over particle size and composition while raising production to industrial scale poses substantial challenges to existing methodologies.

Cathodic corrosion is a wet chemistry method for NP production, but it is fundamentally different from other wet chemistry methods. ${ }^{23,24}$ Cathodic polarization of wires in an electrolyte containing nonreducible cations is believed to lead

Received: November 28, 2017

Accepted: February 15, 2018

Published: February 15, 2018 


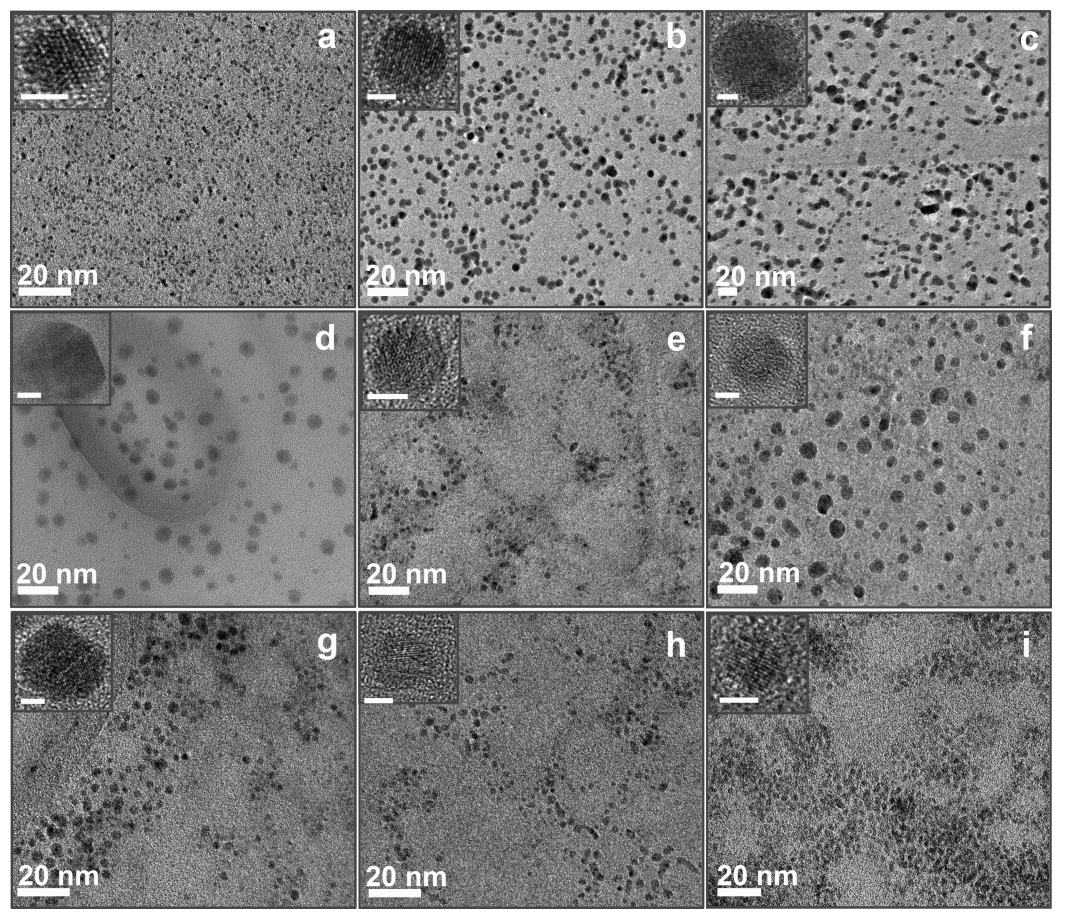

Figure 1. TEM/HRTEM images. All of the insets in the upper left corner have a scale bar of $2 \mathrm{~nm}$, whereas all of the main figures have a scale bar of $20 \mathrm{~nm}$. Pt NPs produced in $0.1 \mathrm{M} \mathrm{NaOH}$ (a), Au NPs produced in $1 \mathrm{M} \mathrm{Ca}\left(\mathrm{NO}_{3}\right)_{2}$ (Au-I) (b), Au NPs produced in $0.3 \mathrm{M} \mathrm{Na}_{2} \mathrm{SO}_{4}(\mathrm{Au}-\mathrm{II})$ (c), Ag NPs produced in $0.1 \mathrm{M} \mathrm{NaOH}(\mathrm{d}), \mathrm{Pd} \mathrm{NPs}$ produced in $0.3 \mathrm{M} \mathrm{CaCl}_{2}$ (e), $\mathrm{Rh}$ NPs produced in $0.3 \mathrm{M} \mathrm{CaCl}_{2}$ (f), Ir NPs produced in $0.3 \mathrm{M} \mathrm{CaCl}_{2}$ $(\mathrm{g}), \mathrm{Cu}$ NPs produced in $0.3 \mathrm{M} \mathrm{CaCl}_{2}(\mathrm{~h})$, and $\mathrm{Ni}$ NPs produced in $0.3 \mathrm{M} \mathrm{Na}_{2} \mathrm{SO}_{4}$ (i). All of the bulk wires were treated at $\pm 10 \mathrm{~V}$ with a square waveform at a frequency of $100 \mathrm{~Hz}$ and were submerged in various electrolyte solutions with $5 \mathrm{wt} \% \mathrm{PVP}$. According to our empirical experience and earlier work, ${ }^{23}$ different electrolytes were chosen for different metals to guarantee efficient NP production. Here, using the positive voltage is essential to facilitate the detachment of NPs from the electrode surface. ${ }^{23}$

to short-lived metal anionic clusters, which are stabilized by their interaction with the electrolyte cations. These anionic clusters survive only within a water-free layer near the electrode where water is primarily reacting to hydrogen. After exiting this layer, the anions are rapidly oxidized to their metallic state by water from the electrolyte solution. Subsequent nucleation and collisional growth of these prenucleation clusters is then believed to lead to NP formation. Synthesis of nanostructured materials by applying an alternating potential to metallic electrodes has been reported in various previous publications, ${ }^{25-31}$ but our interpretation of the NP formation is fundamentally different from that reported by others. For instance, in the recent work by Cloud et al., ${ }^{27}$ it is assumed that metallic oxides from anodic corrosion are subsequently reduced during cathodic treatment to form nanocrystals. We have shown in our earlier publications that NPs can form under cathodic treatments only, but that the method for NP production may be enhanced by applying alternating current (AC), even with a cathodic bias. ${ }^{23}$

One of the main problems of the cathodic corrosion method arises from significant agglomeration of the NPs during synthesis. This prohibits a large surface-to-volume ratio that would be benificial for catalysis, but also makes the particles extremely large and highly polydisperse. ${ }^{23}$ Moreover, the use of highly concentrated electrolytes ( $>1 \mathrm{M})$ complicates the washing procedures to obtain clean products. Despite its simplicity and versatility, upscaling of the cathodic corrosion method remains unexplored and this is expected to be a dire necessity for entering industrial markets.

Here, we show that cathodic corrosion can be modified to produce nonaggregated nanocrystals and nanoalloys with catalytic and (tunable) optical properties. This is achieved by simply adding a stabilizer (poly(vinylpyrrolidone), PVP) to the electrolyte, in which a pair of wires is submerged. The wires are connected to a square-wave AC source. The negative polarity is used to drive the cathodic corrosion, whereas the positive polarity helps to detach the NPs from the wire surface. To further enhance the NP production, we integrate ultrasonication into the production cell. Even higher production rates can be realized through implementing a "comb" electrode system, corroding multiple wires in parallel. To demonstrate the compatibility of thus-produced NPs with electrocatalytic applications, in situ impregnation was carried out to create a carbon-supported Pt/C-cathodic corrosion (CC) catalyst, which is shown to have equal or better catalytic performance for methanol oxidation in comparison with the commercial $\mathrm{Pt}$ / C-Johnson Matthey (JM) catalyst. In addition, we show that the method can produce nonaggregated alloy NPs, the average composition of which can be tailored through the composition of parent wires. Ultraviolet-visible (UV-vis) spectroscopy of the thus-prepared $\operatorname{Ag}_{x} \mathrm{Au}_{100-x}$ nanoalloys shows shifted absorption peaks as compared to pure $\mathrm{Ag}$ and $\mathrm{Au}$ NPs. The modified protocol for NP synthesis by cathodic corrosion presented here is a step forward to further use of this method in academic research as well as in its practical upscaling.

\section{RESULTS}

A pair of metallic wires was mounted to a custom-made power system (see details in Experimental Section), which enables switching the polarity of applied voltage $( \pm 10 \mathrm{~V})$ at a frequency of $100 \mathrm{~Hz}$. The wires were submerged ca. $2 \mathrm{~mm}$ in the electrolytes containing cations $\left(\mathrm{Na}^{+}\right.$and $\mathrm{Ca}^{2+}$ ) and PVP (cf. 

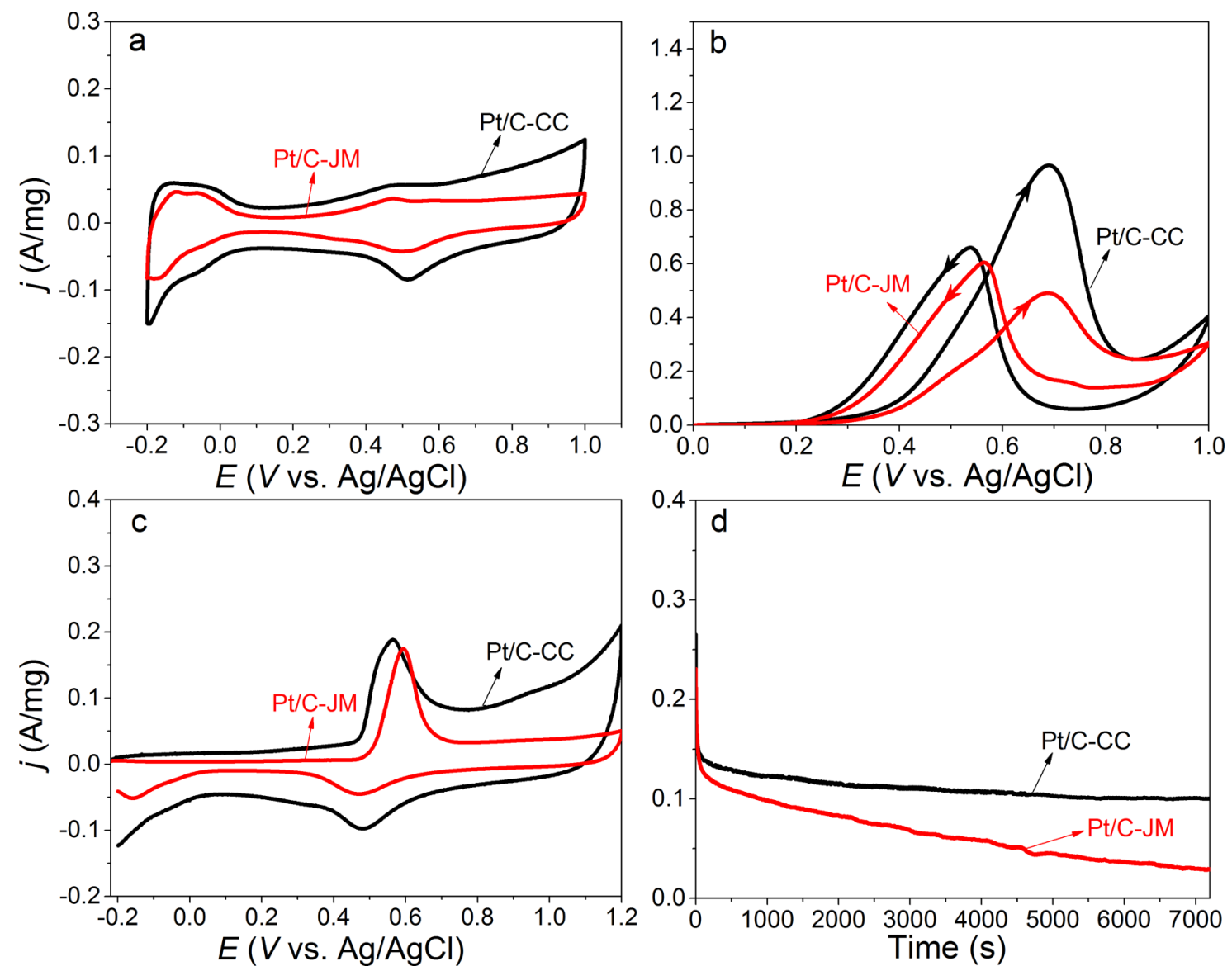

Figure 2. Cyclic voltammograms (CVs) of Pt/C-CC and Pt/C-JM catalysts in $0.1 \mathrm{M} \mathrm{HClO}_{4}$ at a scan rate of $50 \mathrm{mV} / \mathrm{s}(\mathrm{a})$ and in $0.1 \mathrm{M} \mathrm{HClO}$ and $1.0 \mathrm{M} \mathrm{CH}_{3} \mathrm{OH}$ at a scan rate of $20 \mathrm{mV} / \mathrm{s}$ (b). CO stripping voltammograms (c) of Pt/C-CC and Pt/C-JM catalyst in $0.1 \mathrm{M} \mathrm{HClO}_{4}$ at a scan rate of $50 \mathrm{mV} / \mathrm{s}$. Chronoamperograms (d) at $0.45 \mathrm{~V}$ of Pt/C-CC and Pt/C-JM catalyst in $0.1 \mathrm{M} \mathrm{HClO}_{4}$ and $1.0 \mathrm{M} \mathrm{CH}_{3} \mathrm{OH}$. The current density in the CVs is normalized by the respective mass of Pt loading.

Experimental Section) for generating NPs. ${ }^{23}$ We used transmission electron microscopy (TEM), high-resolution TEM (HRTEM), dynamic light scattering, and nanoparticle-tracking analysis to demonstrate the formation of nonaggregated NPs (Pt, Pd, $\mathrm{Au}, \mathrm{Ag}, \mathrm{Cu}, \mathrm{Rh}, \mathrm{Ir}$, and $\mathrm{Ni}$ ) and nanoalloys $\left(\mathrm{Pt}_{50} \mathrm{Au}_{50}\right.$, $\mathrm{Pd}_{50} \mathrm{Au}_{50}$, and $\mathrm{Ag}_{x} \mathrm{Au}_{100-x}, x=10,30,50,70$, and 90). Energydispersive X-ray (EDX) spectroscopy line scan and elemental mapping were used to prove the formation of $\mathrm{Pt}_{50} \mathrm{Au}_{50}$, $\mathrm{Pd}_{50} \mathrm{Au}_{50}$, and $\mathrm{Ag}_{x} \mathrm{Au}_{100-x}$ nanoalloys. To demonstrate the functional properties of the NPs, we studied the electrocatalytic properties of Pt NPs for methanol oxidation reaction (MOR) and optical properties of $\mathrm{Ag}_{x} \mathrm{Au}_{100-x}$ nanoalloys by using $\mathrm{UV}-$ vis.

2.1. Producing Nearly Monodisperse Monometallic NPs. TEM was used to study the monodispersity and crystallinity of the generated NPs. Figure 1 shows the TEM/ HRTEM images of various NPs $(\mathrm{Pt}, \mathrm{Au}, \mathrm{Ag}, \mathrm{Pd}, \mathrm{Rh}, \mathrm{Ir}, \mathrm{Cu}$, and $\mathrm{Ni}$ ) produced by the cathodic corrosion method in the presence of the PVP stabilizer. A photograph of the colloidal $\mathrm{NP}$ solutions is presented in Figure $\mathrm{S} 1$ in the Supporting Information (SI). As can be seen from the TEM images, most NPs are spherical and uniformly dispersed. Lattice fringes can be clearly seen in the HRTEM images (insets in the left upper corners), evidencing crystallinity. For example, the lattice spacing of Ag NPs is estimated to be $2.29 \pm 0.05 \AA$, which is close to that of face-centered cubic (fcc) $\mathrm{Ag}$ with a lattice spacing of $2.36 \AA$; the estimated lattice spacing for Pt $(2.245 \pm$
$0.045 \AA$ ) agrees with the fcc Pt lattice spacing of $2.25 \AA$. The presence of the corresponding elements was confirmed by the EDX analysis (cf. Figure S2). Particle size distributions were estimated from the TEM images and show that Pt, Au-I (produced in $\mathrm{Ca}\left(\mathrm{NO}_{3}\right)_{2}$ ), Au-II (produced in $\mathrm{Na}_{2} \mathrm{SO}_{4}$ ), $\mathrm{Ag}, \mathrm{Pd}$, $\mathrm{Rh}, \mathrm{Ir}, \mathrm{Cu}$, and Ni NPs have an average diameter of ca. 2.1, 4.4, $9.4,8.6,4.5,6.3,5.2,4.7$, and $4.2 \mathrm{~nm}$, respectively (cf. Figure S3, together with the associated standard deviations). Interestingly, the size of Au-I NPs is approximately half the size of the Au-II NPs, indicating that the nature of the cations in the electrolyte impacts the particle size and morphology. Cations presumably influence the metastability of prenucleation clusters generated cathodically, ${ }^{32}$ thus affecting the final properties of the NPs.

2.2. Creating Electrocatalytically Active Nanocatalysts by in Situ Impregnation. This subsection integrates the generation of nonaggregated NPs by cathodic corrosion into an existing nanofabrication process, such as creating electrocatalysts for an electrode reaction in fuel cells. To create a material that is close to commercially available materials, we used in situ impregnation for loading the generated NPs onto Vulcan XC-72 (cf. Figure S4). Vulcan XC-72 was directly dispersed into the electrolyte in which cathodic corrosion was taking place. The amount of Pt NPs ( 8.5 wt \% determined by inductively coupled plasma optical emission spectrometry, ICPOES) generated can be controlled by the etching time. The PVP was removed from the surface of the NPs by reflux in acetic acid (for details see Experimental Section). Here, we 

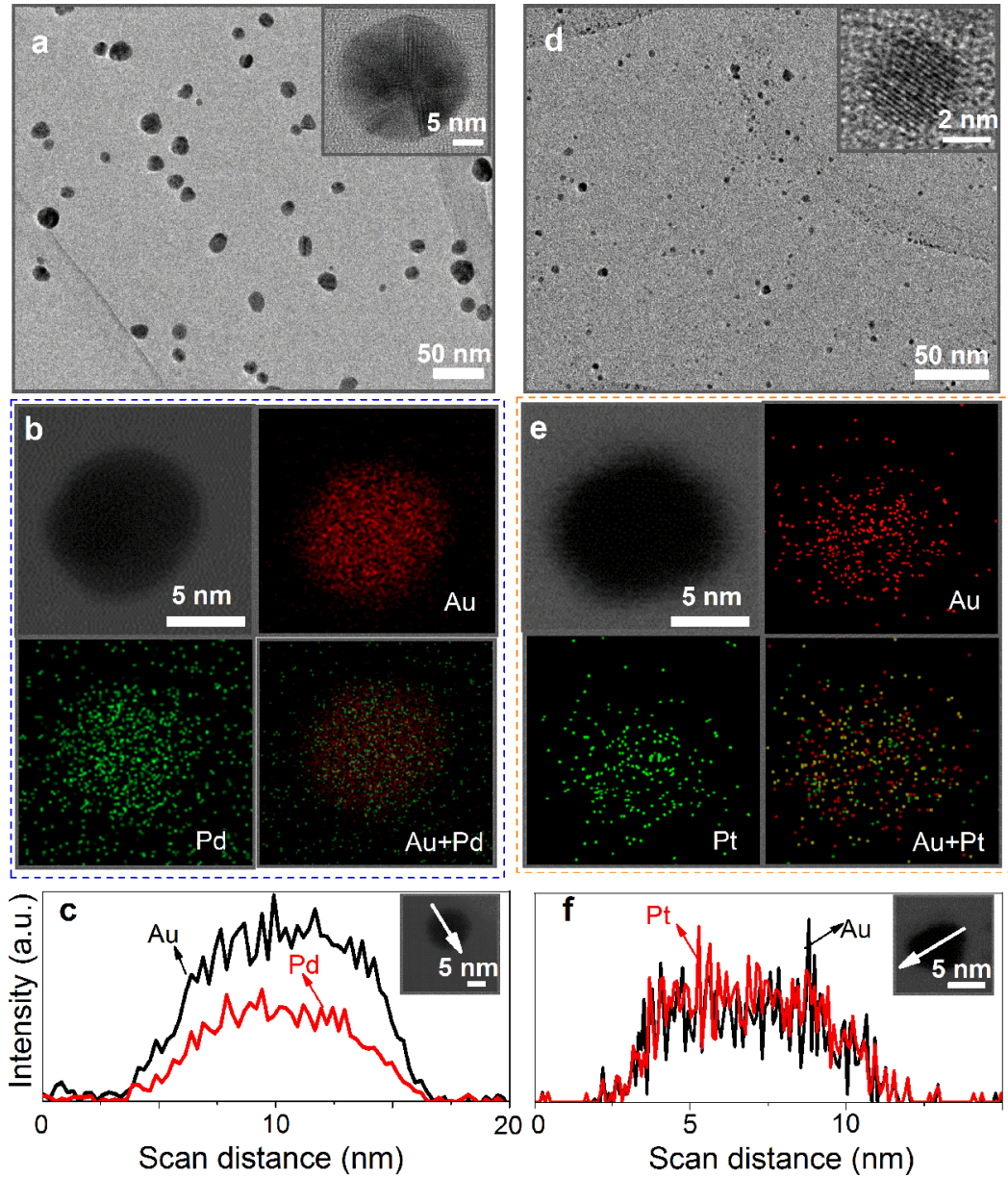

Figure 3. Composition analysis of nanoalloys generated by cathodic corrosion. TEM (a, d)/HRTEM images (insets in (a) and (d)), scanning TEM (STEM) images, element mapping analysis (b, e), and line scan profiles (c, f) of randomly selected Pd-Au $(a-c)$ and Pt--Au alloy NPs $(d-f)$. In the elemental mapping, Au is color-coded red, whereas Pt and Pd are marked as green.

show the example of Pt/C-CC (cf. Figure S4a: before rinsing; Figure 4b: after rinsing) as an electrocatalyst for methanol oxidation reaction (MOR), benchmarked to commercial Pt/CJM (cf. Figure S4c). The corresponding electrochemically active surface areas (ECSAs) were estimated as 70.3 and 62.8 $\mathrm{m}^{2} / \mathrm{g}$ by integrating the hydrogen desorption charge from -0.2 to $0.1 \mathrm{~V}$ (cf. Figure 2a). The larger ECSA for Pt/C-CC can be due to the smaller particle sizes ( $2.1 \mathrm{vs} 4.0 \mathrm{~nm}$ for Pt/C-JM). In Figure $2 \mathrm{~b}$, the methanol oxidation activity is compared between the Pt/C-CC and Pt/C-JM catalysts. In the forward scan, the mass activity of $\mathrm{Pt} / \mathrm{C}$-CC is nearly 2-fold higher than that of $\mathrm{Pt} / \mathrm{C}$-JM. With respect to the specific activity (cf. Figure S5, i.e., normalized to the ESCA), Pt/C-CC $\left(1.37 \mathrm{~mA} / \mathrm{cm}^{2}\right)$ is ca. 1.7 times higher (Pt/C-JM: $0.79 \mathrm{~mA} / \mathrm{cm}^{2}$ ). Importantly, Pt/C-CC also gives rise to larger $j_{\mathrm{f}} / j_{\mathrm{b}}$ ratio (where $j_{\mathrm{f}}$ and $j_{\mathrm{b}}$ represent the forward and backward peak current density) as compared to the Pt/C-JM (Pt/C-CC: 1.5; Pt/C-JM: 0.8), suggesting a greater $\mathrm{CO}$ tolerance for $\mathrm{Pt} / \mathrm{C}-\mathrm{CC} .^{33,34}$ To further substantiate this, we show the CO-stripping curves on $\mathrm{Pt} / \mathrm{C}-\mathrm{CC}$ and $\mathrm{Pt} / \mathrm{C}$ $\mathrm{JM}$ catalysts (cf. Figure 2c). Both the onset and peak potentials of CO-stripping for $\mathrm{Pt} / \mathrm{C}$-CC catalyst $(0.44$ and $0.56 \mathrm{~V})$ are more negative than those of Pt/C-JM (0.47 and $0.60 \mathrm{~V})$, showing that $\mathrm{CO}$ is more easily oxidized from the surface of $\mathrm{Pt}$ / C-CC catalyst. Furthermore, chronoamperometric curves demonstrate a slower decay rate of the $\mathrm{Pt} / \mathrm{C}-\mathrm{CC}$ due to the higher surface area and the greater CO tolerance (cf. Figure 2d).

2.3. Creating Nanoalloys from the Corresponding Parent Alloy Wires. The cathodic corrosion method is capable of producing alloy NPs by employing parent alloy wires. ${ }^{35}$ Figure 3 shows the TEM/HRTEM images (insets) of alloy $\mathrm{Pt}-\mathrm{Au}$ and $\mathrm{Pd}-\mathrm{Au} \mathrm{NPs}$, line-scanned EDX profiles, and elemental mappings. Similar to the monometallic NPs, the nanoalloys are also largely nonaggregated (cf. Figure 3a,b). The associated size distributions are shown in Figure S6. Specifically, the mean sizes of $\mathrm{Pd}-\mathrm{Au}$ and $\mathrm{Pt}-\mathrm{Au} \mathrm{NPs}$ are ca. 17.2 and $7.0 \mathrm{~nm}$ (cf. Figure S6), respectively, which is slightly larger than those of the corresponding monometallic NPs.

With respect to the alloy NPs, we used X-ray diffraction to identify the alloy phases (cf. Figure S7). The diffraction pattern of $\mathrm{Au}-\mathrm{Pt} \mathrm{NPs}$ shows a negative shift (an increase of lattice spacing) in comparison with that of Pt (JCPDS-04-0802), whereas a positive shift in $\mathrm{Au}-\mathrm{Pd} \mathrm{NPs}$ (a decrease in lattice spacing) occurs in reference to that of Au (JCPDS-04-0784). These shifts suggest the alloy structure of both $\mathrm{Au}-\mathrm{Pt}$ and $\mathrm{Au}-$ Pd NPs. Besides the overview of the alloy states, we probe the single NPs by using EDX elemental mapping and line scan profiles. Both elements (cf. Figure 3b,e) are distributed throughout the randomly selected NPs. The line scan profiles show that the collected signal of $\mathrm{Pt}-\mathrm{Au}$ NPs (Figure 3f) presents a consistent trend of elemental distribution to its bulk 

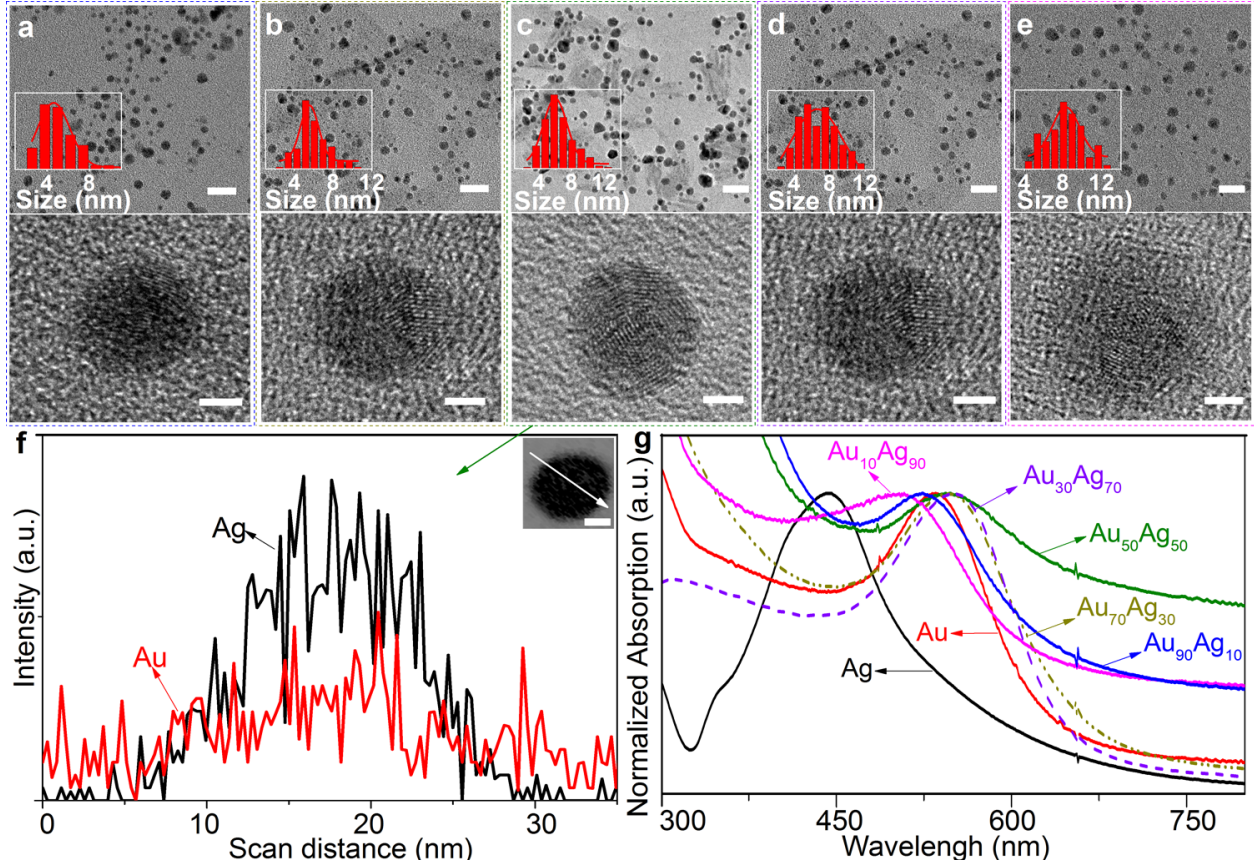

Figure 4. Analysis and characterization of $\mathrm{AuAg}$ nanoalloys. TEM images of $\mathrm{Au}_{90} \mathrm{Ag}_{10}, \mathrm{Au}_{70} \mathrm{Ag}_{30}, \mathrm{Au}_{50} \mathrm{Ag}_{50}, \mathrm{Au}_{30} \mathrm{Ag}_{70}$, and $\mathrm{Au}_{10} \mathrm{Ag}_{90}$ nanoalloys (a-e). Particle size distributions are added as insets of the TEM images in the first row (scale bar $20 \mathrm{~nm}$ ) and the corresponding HRTEM images (scale bar $2 \mathrm{~nm}$ ) are assembled in the second row. (f) Line scan profiles of $\mathrm{Au}_{50} \mathrm{Ag}_{50}$ nanoalloys with STEM image (inset, scale bar $5 \mathrm{~nm}$ ); UV-vis absorption spectra of monometallic ( $\mathrm{Au}, \mathrm{Ag}) \mathrm{NPs}$ and the $\mathrm{Ag}_{x} \mathrm{Au}_{100-x}$ nanoalloys $(\mathrm{g})$.

counterpart $\mathrm{Pt}_{50} \mathrm{Au}_{50}$; however, a slightly lower amount of $\mathrm{Pd}$ is in the NP as compared to that of bulk $\mathrm{Pd}_{50} \mathrm{Au}_{50}$ (Figure $3 \mathrm{c}$ ). In addition, we used ICP-OES to determine the approximate average compositions of $\mathrm{Pt}-\mathrm{Au}$ (50:41) and $\mathrm{Pd}-\mathrm{Au}$ (38:50) NPs. Such differences in NP composition with the nominal one are probably associated with the different etching rates of each element in the bulk alloys. ${ }^{35}$

2.4. Surface Plasmon Absorption Band of $\mathrm{Ag}_{x} \mathrm{Au}_{100-x}$ Nanoalloys. To study the tunability of the nanoalloys, we have made a number of $\mathrm{Ag}_{x} \mathrm{Au}_{100-x}$ nanoalloys (cf. Figure $4 \mathrm{a}-\mathrm{e}$ ) from wires with different $\mathrm{Au}-\mathrm{Ag}$ nominal compositions as given in Table 1. The UV-vis absorption spectra of the NPs exhibit a single peak for all of the samples, as shown in Figure $4 \mathrm{~g}$, thereby confirming the formation of alloy phase. In addition, the $\mathrm{Au}_{50} \mathrm{Ag}_{50}$ nanoalloy is characterized by a line

Table 1. Average Diameters Determined by Analyzing TEM Images and Peak Absorption Data $\left(\lambda_{\max }\right)$ for $\mathrm{Au}$ and $\mathrm{Ag}$ Alloy NPs ${ }^{a}$

\begin{tabular}{lrrrccc} 
& \multicolumn{2}{c}{$\begin{array}{c}\text { nominal } \\
\text { atomic } \\
\text { percentage } \\
(\%)\end{array}$} & & & & \\
samples & $\mathrm{Au}$ & $\mathrm{Ag}$ & $\begin{array}{c}(\mathrm{nm}) \\
\text { average diameter }\end{array}$ & $\begin{array}{c}\text { standard deviation } \\
(\mathrm{nm})\end{array}$ & $\begin{array}{c}\lambda_{\text {max }} \\
(\mathrm{nm})\end{array}$ \\
$\mathrm{nyynnnn} \mathrm{Au}$ & 100 & 0 & $4.4^{b}$ & 1.3 & 533 \\
$\mathrm{Au}_{90} \mathrm{Ag}_{10}$ & 90 & 10 & 5.1 & 1.7 & 524 \\
$\mathrm{Au}_{70} \mathrm{Ag}_{30}$ & 70 & 30 & 5.9 & 1.6 & 547 \\
$\mathrm{Au}_{50} \mathrm{Ag}_{50}$ & 50 & 50 & 6.4 & 1.8 & 548 \\
$\mathrm{Au}_{30} \mathrm{Ag}_{70}$ & 30 & 70 & 6.8 & 2.0 & 552 \\
$\mathrm{Au}_{10} \mathrm{Ag}_{90}$ & 10 & 90 & 8.2 & 1.9 & 505 \\
$\mathrm{Ag}$ & 0 & 100 & $8.6^{b}$ & 2.7 & 442
\end{tabular}

${ }^{a}$ Over 100 particles were used to estimate the particle size of each sample. ${ }^{b}$ Figure S3 provides the size distributions. scan profile (cf. Figure 4f). The peaks shift according to their nominal composition for the $\mathrm{Ag}, \mathrm{Au}_{10} \mathrm{Ag}_{90}, \mathrm{Au}_{90} \mathrm{Ag}_{10}$, and $\mathrm{Au}$ NPs. The pure $\mathrm{Ag}$ and $\mathrm{Au}$ NPs show characteristic peaks at 442 and $533 \mathrm{~nm}$, which are red-shifted with respect to the literature values for Ag NPs $(410 \mathrm{~nm})$ and for Au NPs $(525 \mathrm{~nm}))^{36,37}$ Such red-shifted peaks are similar to those reported by Guisbiers et al. $^{38}$ and explained by the increased refractive index due to the presence of solutes/PVP in the medium. ${ }^{39-41}$ Note that the average size of the NPs determined by analyzing the TEM images (the fourth column in Table 1) varies monotonically with the sample composition, but not with the absorption peaks. The UV peaks for the $\mathrm{Au}_{90} \mathrm{Ag}_{10}$ and $\mathrm{Au}_{10} \mathrm{Ag}_{90}$ nanoalloys are in between the peaks for monometallic $\mathrm{Au}$ and $\mathrm{Ag}$ NPs because the larger amount of Au or Ag retains the NP size of their monometals (cf. Table 1) and, as a result, the composition change appears to be mainly responsible for the peak shift. The peak shifts for $\mathrm{Au}_{30} \mathrm{Ag}_{70}, \mathrm{Au}_{50} \mathrm{Ag}_{50}$ and $\mathrm{Au}_{70} \mathrm{Ag}_{30}$ do not follow a clear composition trend because the size change seems to dominate in this composition range, and these sizes are relatively far from those obtained for the pure parent metals (see Table 1).

\section{DISCUSSION}

In this work, we showed that the cathodic corrosion method can be modified to make nonaggregated nanocrystals and nanoalloys by adding $\mathrm{PVP}^{42}$ to the electrolytes and by ultrasonication to help the transfer of NPs from the "point source" (a bulk wire with a diameter of $0.1-0.2 \mathrm{~mm}$ and immersed 1-2 $\mathrm{mm}$ in the electrolytes; see details in Experimental Section) to the bulk of the electrolyte. We assume that a cloud of metal prenucleation clusters is formed near the metallic wires by applying a negative potential. These metallic clusters collide to form NPs and their growth/further aggregation is terminated by coating the particle surface with 
Table 2. Summarizing the NPs Synthesized by Cathodic Corrosion Reported in Literature and This Work

\begin{tabular}{|c|c|c|c|c|}
\hline material class & specific materials & references & this work & notes \\
\hline metals & $\mathrm{Pt}, \mathrm{Au}, \mathrm{Rh}, \mathrm{Ag}, \mathrm{Re}, \mathrm{Ir}, \mathrm{Cu}, \mathrm{Pd}, \mathrm{Ni}$ & $\begin{array}{l}23,24 \text {, this } \\
\text { work }\end{array}$ & Figure 1 & $\begin{array}{l}\text { all NPs are aggregated } \\
\text { in literature }\end{array}$ \\
\hline alloys & $\begin{array}{l}\mathrm{Pt}_{90} \mathrm{Rh}_{10}, \mathrm{Pt}_{70} \mathrm{Rh}_{30}, \mathrm{Pt}_{20} \mathrm{Rh}_{80}, \mathrm{AuCo} \mathrm{AuCu}, \mathrm{FeCo}, \mathrm{Pt}_{95} \mathrm{Ru}_{5}, \mathrm{Pt}_{80} \mathrm{Ir}_{20}, \mathrm{Pt}_{50} \mathrm{Ni}_{50}, \mathrm{Pt}_{90} \mathrm{~Pb}_{10} \\
\quad \mathrm{Pt}_{70} \mathrm{Bi}_{30}, \mathrm{Pt}_{50} \mathrm{Au}_{50}, \mathrm{Pd}_{50} \mathrm{Au}_{50}, \mathrm{Au}_{10} \mathrm{Ag}_{90}, \mathrm{Au}_{30} \mathrm{Ag}_{70}, \mathrm{Au}_{50} \mathrm{Ag}_{50}, \mathrm{Au}_{70} \mathrm{Ag}_{30}, \mathrm{Au}_{90} \mathrm{Ag}_{10}\end{array}$ & $\begin{array}{l}24,45,35 \\
\text { this work }\end{array}$ & $\begin{array}{l}\text { Figures } 3 \\
\text { and } 4\end{array}$ & $\begin{array}{l}\text { all NPs are aggregated } \\
\text { in literature }\end{array}$ \\
\hline nanocomposites & $\mathrm{Pt} / \mathrm{C}-\mathrm{CC}$ & this work & Figure S4 & $\begin{array}{l}\text { catalytic properties in } \\
\text { MOR }\end{array}$ \\
\hline oxides & $\mathrm{H}_{2} \mathrm{WO}_{4}, \mathrm{BiVO}_{4}, \mathrm{TiO}_{2}$ & 46,47 & & $\begin{array}{l}\text { nanoplates, nanowires, } \\
\text { star-shaped NPs }\end{array}$ \\
\hline
\end{tabular}

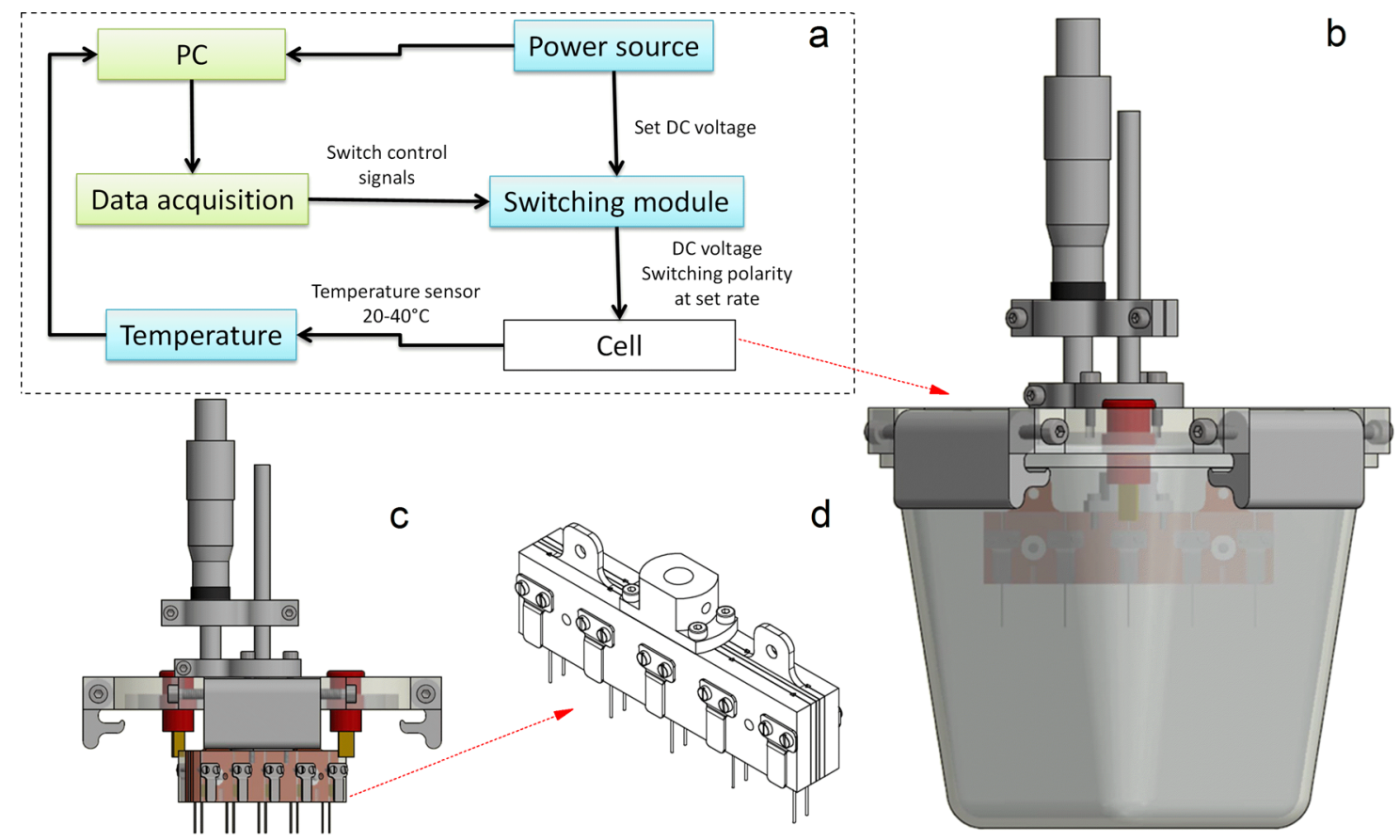

Figure 5. Schematic illustration of the "comb-electrode" setup. The block diagram of the global design of the setup (a), the complete cell system (b), the electrode feeding component (c), and an enlarged comb consisting of five electrode pairs (d). A micrometer screw mounted on the comb electrodes was used to precisely adjust their submersion depth (measured from the moment the electrode touches the liquid surface) in the liquid.

PVP (cf. NP stability test shown in Figure S8 and the associated discussions). ${ }^{42}$

Another practical effect of ultrasonication is to disperse particles from the surface of the electrolyte solution into the bulk of the solution. A fraction of particles is carried by the bubbles $^{43}$ to the interface between the liquid and the air above the electrolyte. Collapse of these bubbles makes the particles inside the bubbles deposit at the interface. As a result, NP clouds spread over like ripples centered away from the wire and can be redispersed into the solution upon ultrasonication. In addition, the ultrasonication increases the rate of bubble displacement, thus increasing the etching rate by a factor of 5 approximately (and nanoparticulate production rate as shown in Figure S9).

In previous work, we and others have managed to produce a variety of metallic aggregates and some alloys, which are summarized in Table 2 for drawing a comparison with this work. We have also shown that for Pt NPs, the size of the NPs, and to some extent also the shape and faceting, can be controlled by the (average) current density with which the process is driven. ${ }^{44}$

For alloy NPs, we have shown that the bulk composition is roughly retained in the NPs generated by cathodic corrosion, although differences may appear because of different rates of cathodic corrosion of different elements and because of local surface segregation. ${ }^{35}$ The electrolytes presumably influence the metastability of prenucleation clusters generated cathodically, ${ }^{32}$ thus affecting the etching process and the interactions with the parent metal wires. A careful selection of a proper electrolyte is our future top priority for making nanoalloys that retain the composition of the parental wires. Based on our results with a compositional series of $\mathrm{Ag}_{x} \mathrm{Au}_{100-x}$ alloys (cf. Table 1 and Figure 4), we found that their size and composition simultaneously change when cathodically etching the corresponding alloy wires. To improve their independent control, one should probably adjust the current density in this process to the desired NP size. This would require a matrix of experiments tuning the current density for each alloy composition.

3.1. Scaling Up the NP Production by Comb Electrode Concept. This section discusses the possible upscaling of the NP production by cathodic corrosion. The etching rate of the method is ultimately related to the applied current density during the cathodic phase of the AC cycle ${ }^{44}$ (see also Figure S9 and associated discussions).

The following discussions mainly center on increasing the current by designing comb electrodes, i.e., parallelization of electrodes (see Figure 5). It is estimated that the current density can be increased by one order of magnitude without leading to glow discharge, as compared to the classical setup 
Table 3. Electrolytes Used in Cathodic Corrosion for NP Production ${ }^{a}$

\begin{tabular}{ccccc} 
electrolytes & $1 \mathrm{M} \mathrm{Ca}\left(\mathrm{NO}_{3}\right)_{2}$ & $0.3 \mathrm{M} \mathrm{Na}_{2} \mathrm{SO}_{4}$ & $0.1 \mathrm{M} \mathrm{NaOH}$ & $0.3 \mathrm{M} \mathrm{CaCl}_{2}$ \\
$\mathrm{NPs}$ & $\mathrm{Au}$ & $\mathrm{PtAu}, \mathrm{Ag}_{x} \mathrm{Au}_{100-x}, \mathrm{Ni}$ & $\mathrm{Ag}$ & $\mathrm{Pd}, \mathrm{Rh}, \mathrm{Ir}, \mathrm{Cu}, \mathrm{PdAu}$ \\
${ }^{a}$ For $\mathrm{Ag}_{\mathrm{x}} \mathrm{Au}_{100-x}, x=0,10,30,50,70,90$, and 100. & & & \\
\hline
\end{tabular}

(cf. production rate determined by ICP-OES in Figure S9). Additionally, we can also increase the number of electrode pairs associated with the power source (Delta SM120-13 120V/13A, cf. Figure S10). For our first generation (five electrode pairs in Figure S10, see a video recorded during NP production, also available in the $\mathrm{SI}$ ), it would increase the production rate by a factor of ca. 50. Based on the power input $(30 \mathrm{~V}, 0.1 \mathrm{~A})$ and the ICP-OES-determined production rate (ca. $30 \mathrm{mg} / \mathrm{h}$, cf. Figure S9), we estimate that energy consumption of $1 \mathrm{kWh}$ leads to 10 $\mathrm{g}$ Pt NPs in $1.0 \mathrm{M} \mathrm{NaOH}$. Considering that the NP production consumes electrical energy exclusively, solar panels can be used to power this method for making an even greener process.

Electronic waste has been identified as a worldwide environmental threat. ${ }^{48}$ Copper is largely used in electronic wires/cables and printed circuit boards. Considering the fact that copper NPs were successfully produced by cathodic corrosion (cf. Figure $1 \mathrm{~h}$ ), we believe that this method can be used to convert these electronic waste to copper NPs, which could either be further metallurgically processed or be directly used in heat-transfer fluids. ${ }^{49}$

\section{CONCLUSIONS}

We have developed a modified protocol for cathodic corrosion of a bulk wire to nonaggregated nanoparticles (NPs) in a way that allows scaling up. Producing nonaggregated NPs and nanoalloys was achieved by adding poly(vinylpyrrolidone) (PVP) as a stabilizer in the electrolyte solution, where the cathodic corrosion of the corresponding wires took place under ultrasonication-promoting particle-PVP interactions. By parallelization of the comb electrodes, this synthesis protocol has the potential for scaling up production of ca. $10 \mathrm{~g} \mathrm{Pt} \mathrm{NPs/kWh}$. We showed the possibility of preparing functional NPs by the example of carbon-supported Pt NPs as electrocatalysts for methanol oxidation reaction, demonstrating comparable or even higher mass activity and superior durability benchmarked to the commercial catalyst. Nonaggregated nanoalloys are also easily produced using this method by etching parent alloy wires. The AgAu nanoalloys produced by cathodic corrosion showed the tunability of the UV-vis absorption peaks, but the simultaneous size and composition change of the nanoalloys would require further study to achieve their separate control. It is believed that this synthetic protocol can enhance and supplement the rapidly growing uses of NPs in academic and industrial pursuits.

\section{EXPERIMENTAL SECTION}

5.1. Materials and Chemicals. $\mathrm{Ca}\left(\mathrm{NO}_{3}\right)_{2} \cdot 4 \mathrm{H}_{2} \mathrm{O}$ and Nafion 117 solution ( $5 \%$ in a mixture of lower aliphatic alcohols and water) were purchased from Sigma-Aldrich. $\mathrm{NaOH}$ (98.5\%) and poly(vinylpyrrolidone) $(\mathrm{PVP}$, molecular weight $\approx 58000)$ were obtained from ACROS. $\mathrm{CaCl}_{2} \cdot 2 \mathrm{H}_{2} \mathrm{O}$ was purchased from J. T. Baker. Vulcan XC-72 carbon powder (XC-72 C with Brunauer-Emmett-Teller surface area of $250 \mathrm{~m}^{2} / \mathrm{g}$ and average particle size of $40-50 \mathrm{~nm}$ ) was purchased from Cabot. Ethanol (absolute) was obtained from Fisher Chemical. Acetic acid (>99.8\%) and perchloric acid solution (70\%) were purchased from Beijing Chemical Works. Commercial Pt/C-JM catalyst was purchased from Johnson Matthey (20 wt \% Pt NPs with an average size of $4.0 \mathrm{~nm}$ on Vulcan XC-72 carbon support). All of the aqueous solutions were prepared using deionized water with a resistivity of $18.2 \mathrm{M} \Omega \mathrm{cm}$. The metallic wires as described below were purchased from different companies. $\mathrm{Cu}$ (99.9\%, $0.12 \mathrm{~mm}$ diameter), $\mathrm{Au}_{50} \mathrm{Pd}_{50}$ (0.125 mm diameter), and Pd (99.99\%, $0.1 \mathrm{~mm}$ diameter) were purchased from Materials Research Sa.r.I, Highways International, H. Drijfhout \& Zoon's Edelmetaalbedrijven B.V., and Alfa Aesar, respectively. $\mathrm{Pt}_{50} \mathrm{Au}_{50}$ (0.3 mm diameter) and $\mathrm{Ir}$ (99.9\%, 0.15 mm diameter) were purchased from Goodfellow. Ag (99.99\%, 0.25 $\mathrm{mm}$ diameter), $\mathrm{Au}$ (99.995\%, $0.1 \mathrm{~mm}$ diameter), and Pt (99.99\%, $0.125 \mathrm{~mm}$ diameter) were purchased from MaTeck. All of the chemicals were used as received without further purification.

5.2. NP Production. A pair of metallic wires was mounted into a customer-made power system (including a direct current power supply: BSI PSM2/5 A). This electrical circuit enables switching the polarity of applied voltage $( \pm 10 \mathrm{~V})$. The frequency was set at $100 \mathrm{~Hz}$ with a duty cycle of $50 \%$. The wires were submerged ca. $2 \mathrm{~mm}$ in the electrolytes (see Table 3), all of which contained ca. 5 wt \% PVP as a stabilizer to inhibit particle agglomeration.

To efficiently disperse the NPs and promote the particle-PVP collisions, an ultrasonicator bath (SONOREX SUPER, RK52H) was integrated into the cell. For cooling the cell, we used the water recirculation in the ultrasonicator bath, whose temperature was monitored by a thermometer.

In situ impregnation to generate $\mathrm{Pt} / \mathrm{C}-\mathrm{CC}$ catalyst was carried out by dissolving the calculated amount of XC-72 (20 wt \%, on the basis of metal mass) into the electrolytes. After sonicating it for ca. $5 \mathrm{~min}$, the etching time was controlled in accordance with the loading amount of NPs. The resulting black solution was centrifuged and washed three times by using ethanol.

5.3. Particle Characterization. Transmission electron microscopy (TEM), high-resolution TEM (HRTEM), and scanning TEM (STEM) were performed on a JEOL JEM-2010F electron microscope operated at $200 \mathrm{kV}$ with the supplied software for automated electron tomography. In addition, a FEI TF20UT/STEM was used for elemental analysis by using an Oxford Instruments EDX detector X$\mathrm{Max}^{\mathrm{N}}$ 100TLE. For the TEM measurements, a drop of the NP dispersion was dispensed onto a $3 \mathrm{~mm}$ carbon-coated copper/ molybdenum grid placed on a piece of filter membrane and drying under ambient conditions.

An energy-dispersive X-ray spectroscopy (EDX) analyzer attached to the TEM operated in the STEM mode was used to analyze the chemical composition of the NPs. The metal contents loaded on Vulcan XC-72 carbon support were measured using inductively coupled plasma optical emission spectroscopy (ICP-OES, PerkinElmer Optima 6300DV spectrometer). Sample preparations for ICPOES measurements are provided in the SI. Dynamic light scattering (Zeta-sizer Nano equipped with a $633 \mathrm{~nm} \mathrm{He}-\mathrm{Ne}$ laser, Malvern, Herenberg, Germany) and nanoparticle tracking analysis (using a Nanosight LM20 equipment from Nanosight Ltd., Amesbury, U.K.) were used for testing the particle stability. Ultraviolet-visible (UVvis) spectroscopy was performed on a spectrophotometer at a resolution of $1 \mathrm{~nm}$. Electrolytes $\left(0.3 \mathrm{M} \mathrm{Na}_{2} \mathrm{SO}_{4}\right)$ with ca. 3 wt \% PVP were used as a blank.

5.4. Electrochemical Measurements. Electrochemical measurements (Figures 2 and S5) were carried out in a standard threeelectrode cell, which was connected to a Bio-logic VMP3 (with EC-lab software version 9.56) potentiostat. A leak-free $\mathrm{Ag} / \mathrm{AgCl}$ (saturated with $\mathrm{KCl}$ ) electrode was used as the reference. The counter electrode was a platinum mesh $\left(1 \times 1 \mathrm{~cm}^{2}\right)$ attached to a platinum wire.

Before the electrochemical test, the $\mathrm{Pt} / \mathrm{C}-\mathrm{CC}$ catalyst obtained via in situ impregnation was redispersed in $30 \mathrm{~mL}$ of acetic acid by ultrasonication, and the resulting mixture was refluxed at $100{ }^{\circ} \mathrm{C}$ for 3 $\mathrm{h}$ to remove the PVP from NP surfaces. Subsequently, the Pt/C-CC 
catalyst was centrifuged, washed thrice with water, and dried at room temperature in a vacuum.

The working electrode was a thin layer of Nafion-impregnated catalyst cast on a vitreous carbon disk. This electrode was prepared by ultrasonically dispersing $5 \mathrm{mg}$ of the Pt/C-CC catalyst in $1 \mathrm{~mL}$ of ethanol containing $0.05 \mathrm{~mL}$ of Nafion solution. After $30 \mathrm{~min}$, appropriate amounts of the ink was dispensed onto the $5 \mathrm{~mm}$ glassy carbon disk electrode, which was then dried in a stream of warm air at $70{ }^{\circ} \mathrm{C}$ for $1 \mathrm{~h}$.

The catalytic performance of $\mathrm{Pt} / \mathrm{C}$-CC for methanol oxidation reaction (MOR) was measured in room temperature by cyclic voltammetry (CV) and chronoamperometry, and was benchmarked to the commercial $\mathrm{Pt} / \mathrm{C}-\mathrm{JM}$ catalyst. The $\mathrm{CV}$ s recorded in argon (purity 99.999\%)-purged $\mathrm{HClO}_{4}(0.1 \mathrm{M})$ between -0.2 and $1.0 \mathrm{~V}$ at a scan rate of $50 \mathrm{mV} / \mathrm{s}$ were used to determine the ESCAs of the electrocatalysts. For electrochemical $\mathrm{CO}$ stripping test, $\mathrm{CO}$ was introduced into $0.1 \mathrm{M} \mathrm{HClO}_{4}$ for $20 \mathrm{~min}$. During this process, the working electrode potential was maintained at $0.15 \mathrm{~V}$. Excess $\mathrm{CO}$ in the electrolyte was then thoroughly purged by using $\mathrm{N}_{2}$ (purity 99.999\%) for $20 \mathrm{~min}$.

The MOR on Pt/C-CC and Pt/C-JM was performed at room temperature in $0.1 \mathrm{M} \mathrm{HClO}_{4}$ and $1.0 \mathrm{M} \mathrm{CH}_{3} \mathrm{OH}$. The CVs of MOR used the potential window of $0-1.0 \mathrm{~V}$ at a scan rate of $20 \mathrm{mV} / \mathrm{s}$, and the current density in the CVs was normalized by the Pt mass measured by ICP-OES (cf. Figure 2) and ECSAs (cf. Figure S5) to obtain the mass and specific activity, respectively.

\section{ASSOCIATED CONTENT}

\section{S Supporting Information}

The Supporting Information is available free of charge on the ACS Publications website at DOI: 10.1021/acsami.7b18105.

Photographs of colloidal NPs produced by cathodic corrosion, EDX data and average sizes of NPs, TEM images of $\mathrm{Pt} / \mathrm{C}-\mathrm{CC}$ and $\mathrm{Pt} / \mathrm{C}-\mathrm{JM}, \mathrm{CVs}$, stability test, increasing NP production in cathodic corrosion, a recorded video of using "comb-electrodes" for NP production, sample preparation for ICP-OES measurements (PDF)

Cathodic corrosion of comb electrodes to nanoparticles (AVI)

\section{AUTHOR INFORMATION}

\section{Corresponding Authors}

*E-mail: jic.feng@gmail.com (J.F.).

*E-mail: jyang@ipe.ac.cn (J.Y.).

*E-mail: m.koper@lic.leidenuniv.nl (M.T.M.K.).

\section{ORCID}

Jicheng Feng: 0000-0003-4799-0630

Marc T. M. Koper: 0000-0001-6777-4594

\section{Author Contributions}

${ }^{\perp}$ J.F. and D.C. contributed equally.

\section{Notes}

The authors declare no competing financial interest.

The manuscript was written through contributions of all of the authors. All of the authors have given approval to the final version of the manuscript.

\section{ACKNOWLEDGMENTS}

The research has received funding from the NWO STW under Grant Agreement No. 00174331 and the National Science Foundation of China (Grant No. 21573240). The authors are grateful to Dr. Junjie $\mathrm{Li}$ for generous help in some TEM measurements.

\section{REFERENCES}

(1) Rao, C. N. R.; Ramakrishna Matte, H. S. S.; Voggu, R; Govindaraj, A. Recent Progress in the Synthesis of Inorganic Nanoparticles. Dalton Trans. 2012, 41, 5089-5120.

(2) Feng, J.; Biskos, G.; Schmidt-Ott, A Toward Industrial Scale Synthesis of Ultrapure Singlet Nanoparticles with Controllable Sizes in a Continuous Gas-Phase Process. Sci. Rep. 2015, 5, No. 15788.

(3) Pfeiffer, T. V.; Feng, J.; Schmidt-Ott, A. New Developments in Spark Production of Nanoparticles. Adv. Powder Technol. 2014, 25, $56-70$.

(4) Pang, X.; Zhao, L.; Han, W.; Xin, X.; Lin, Z. A General and Robust Strategy for the Synthesis of Nearly Monodisperse Colloidal Nanocrystals. Nat. Nanotechnol. 2013, 8, 426-431.

(5) Feng, J.; Ramlawi, N.; Biskos, G.; Schmidt-ott, A. Internally Mixed Nanoparticles from Oscillatory Spark Ablation between Electrodes of Different Materials. Aerosol Sci. Technol. 2018, DOI: $10.1080 / 02786826.2018 .1427852$.

(6) Feng, J.; Hontañón, E.; Blanes, M.; Meyer, J.; Guo, X.; Santos, L.; Paltrinier, L.; Ramlawi, N.; de Smet, L. C. P. M.; Nirschl, H.; Kruis, F. E.; Schmidt-Ott, A.; Biskos, G. Scalable and Environmentally Benign Process for Smart Textile Nanofinishing. ACS Appl. Mater. Interfaces 2016, 8, 14756-14765.

(7) Xu, J.; Zhou, J.; Zhong, Y.; Zhang, Y.; Liu, J.; Chen, Y.; Deng, L.; Sheng, D.; Wang, Z.; Ran, H.; Guo, D. Phase Transition Nanoparticles as Multimodality Contrast Agents for the Detection of Thrombi and for Targeting Thrombolysis: In Vitro and in Vivo Experiments. ACS Appl. Mater. Interfaces 2017, 9, 42525-42535.

(8) Buck, M. R.; Schaak, R. E. Emerging Strategies for the Total Synthesis of Inorganic Nanostructures. Angew. Chem., Int. Ed. 2013, $52,6154-6178$.

(9) Feng, J.; Geutjens, R.; Thang, N. V.; Li, J.; Guo, X.; Kéri, A.; Basak, S.; Galbács, G.; Biskos, G.; Nirschl, H.; Zandbergen, H. W.; Brück, E.; Schmidt-Ott, A. Magnetic Phase Transition in SparkProduced Ternary LaFeSi Nanoalloys. ACS Appl. Mater. Interfaces 2018, 6073-6078.

(10) Aslam, U.; Linic, S. Addressing Challenges and Scalability in the Synthesis of Thin Uniform Metal Shells on Large Metal Nanoparticle Cores: Case Study of Ag-Pt Core-Shell Nanocubes. ACS Appl. Mater. Interfaces 2017, 9, 43127-43132.

(11) Mueller, R.; Mädler, L.; Pratsinis, S. E. Nanoparticle Synthesis at High Production Rates by Flame Spray Pyrolysis. Chem. Eng. Sci. 2003, 58, 1969-1976.

(12) Charitidis, C. A.; Georgiou, P.; Koklioti, M. A.; Trompeta, A.-F.; Markakis, V. Manufacturing Nanomaterials: From Research to Industry. Manuf. Rev. 2014, 1, 11.

(13) Feng, J.; Guo, X.; Ramlawi, N.; Pfeiffer, T. V.; Geutjens, R.; Basak, S.; Nirschl, H.; Biskos, G.; Zandbergen, H. W.; Schmidt-ott, A. Green Manufacturing of Metallic Nanoparticles: A Facile and Universal Approach to Scaling up. J. Mater. Chem. A 2016, 4, $11222-11227$.

(14) Kruis, F. E.; Fissan, H.; Peled, A. Synthesis of Nanoparticles in the Gas Phase for Electronic, Optical and Magnetic Applications-a Review. J. Aerosol Sci. 1998, 29, 511-535.

(15) Wu, L.; Mendoza-Garcia, A.; Li, Q.; Sun, S. Organic Phase Syntheses of Magnetic Nanoparticles and Their Applications. Chem. Rev. 2016, 116, 10473-10512.

(16) Xia, Y.; Xiong, Y.; Lim, B.; Skrabalak, S. E. Shape-Controlled Synthesis of Metal Nanocrystals: Simple Chemistry Meets Complex Physics? Angew. Chem., Int. Ed. 2009, 48, 60-103.

(17) Yang, J.; Ying, J. Y.; Kelley, S.; Ying, J. Y. A General PhaseTransfer Protocol for Metal Ions and Its Application in Nanocrystal Synthesis. Nat. Mater. 2009, 8, 683-689.

(18) Ma, L.; Wang, C.; Gong, M.; Liao, L.; Long, R.; Wang, J.; Wu, D.; Zhong, W.; Kim, M. J.; Chen, Y.; Xie, Y.; Xiong, Y. Control Over the Branched Structures of Platinum Nanocrystals for Electrocatalytic Applications. ACS Nano 2012, 6, 9797-9806.

(19) Zhang, H.; Xia, X.; Li, W.; Zeng, J.; Dai, Y.; Yang, D.; Xia, Y. Facile Synthesis of Five-Fold Twinned, Starfish-like Rhodium 
Nanocrystals by Eliminating Oxidative Etching with a Chloride-Free Precursor. Angew. Chem., Int. Ed. 2010, 49, 5296-5300.

(20) Sun, Y.; Gates, B.; Mayers, B.; Xia, Y. Crystalline Silver Nanowires by Soft Solution Processing. Nano Lett. 2002, 2, 165-168.

(21) Wang, Z.; Wang, H.; Zhang, Z.; Yang, G.; He, T.; Yin, Y.; Jin, M. Synthesis of Pd Nanoframes by Excavating Solid Nanocrystals for Enhanced Catalytic Properties. ACS Nano 2017, 11, 163-170.

(22) Lim, B.; Jiang, M.; Camargo, P. H. C.; Cho, E. C.; Tao, J.; Lu, X.; Zhu, Y.; Xia, Y. Pd-Pt Bimetallic Nanodendrites with High Activity for Oxygen Reduction. Science 2009, 324, 1302-1305.

(23) Yanson, A. I.; Rodriguez, P.; Garcia-Araez, N.; Mom, R. V.; Tichelaar, F. D.; Koper, M. T. M. Cathodic Corrosion: A Quick, Clean, and Versatile Method for the Synthesis of Metallic Nanoparticles. Angew. Chem., Int. Ed. 2011, 50, 6346-6350.

(24) Rodriguez, P.; Tichelaar, F. D.; Koper, M. T. M.; Yanson, A. I. Cathodic Corrosion as a Facile and Effective Method To Prepare Clean Metal Alloy Nanoparticles. J. Am. Chem. Soc. 2011, 133, 1762617629 .

(25) Huang, W.; Chen, S.; Zheng, J.; Li, Z. Facile Preparation of Pt Hydrosols by Dispersing Bulk Pt with Potential Perturbations. Electrochem. Commun. 2009, 11, 469-472.

(26) Leontyev, I.; Kuriganova, A.; Kudryavtsev, Y.; Dkhil, B.; Smirnova, N. New Life of a Forgotten Method: Electrochemical Route toward Highly Efficient Pt/C Catalysts for Low-Temperature Fuel Cells. Appl. Catal., A 2012, 431-432, 120-125.

(27) Cloud, J. E.; McCann, K.; Perera, K. A. P.; Yang, Y. A Simple Method for Producing Colloidal Palladium Nanocrystals: Alternating Voltage-Induced Electrochemical Synthesis. Small 2013, 9, 25322536.

(28) Cloud, J. E.; Yoder, T. S.; Harvey, N. K.; Snow, K.; Yang, Y. A Simple and Generic Approach for Synthesizing Colloidal Metal and Metal Oxide Nanocrystals. Nanoscale 2013, 5, 7368-7378.

(29) Cloud, J. E.; Taylor, L. W.; Yang, Y. A Simple and Effective Method for Controllable Synthesis of Silver and Silver Oxide Nanocrystals. RSC Adv. 2014, 4, 24551.

(30) McCann, K.; Cloud, J. E.; Yang, Y. Alternating Voltage-Induced Electrochemical Synthesis of Colloidal Au Nanoicosahedra. J. Nanopart. Res. 2013, 15, No. 2065.

(31) Jing, M.; Ding, Z.; Hou, H.; Zhang, Y.; Zou, G.; Li, S.; Ji, X. Alternating Voltage Induced Electrochemical Synthesis of ThreeDimensionalization Copper Oxide for Lithium-Ion Battery Application. Chem. Phys. Lett. 2016, 653, 30-34.

(32) Hersbach, T. J. P.; Mints, V. A.; Calle-Vallejo, F.; Yanson, A. I.; Koper, M. T. M. Anisotropic Etching of Rhodium and Gold as the Onset of Nanoparticle Formation by Cathodic Corrosion. Faraday Discuss. 2016, 193, 207-222.

(33) Wang, K.; Sriphathoorat, R.; Luo, S.; Tang, M.; Du, H.; Shen, P. K. Ultrathin $\mathrm{PtCu}$ Hexapod Nanocrystals with Enhanced Catalytic Performance for Electro-Oxidation Reactions. J. Mater. Chem. A 2016, 4, 13425-13430.

(34) Xu, D.; Liu, Z.; Yang, H.; Liu, Q.; Zhang, J.; Fang, J.; Zou, S.; Sun, K. Solution-Based Evolution and Enhanced Methanol Oxidation Activity of Monodisperse Platinum-Copper Nanocubes. Angew. Chem., Int. Ed. 2009, 48, 4217-4221.

(35) Hersbach, T. J. P.; Kortlever, R.; Lehtimäki, M.; Krtil, P.; Koper, M. T. M. Local Structure and Composition of PtRh Nanoparticles Produced through Cathodic Corrosion. Phys. Chem. Chem. Phys. 2017, 19, 10301-10308.

(36) Al-Azawi, M. A.; Bidin, N.; Bououdina, M.; Mohammad, S. M. Preparation of Gold and Gold-silver Alloy Nanoparticles for Enhancement of Plasmonic Dye-Sensitized Solar Cells Performance. Sol. Energy 2016, 126, 93-104.

(37) Plowman, B. J.; Sidhureddy, B.; Sokolov, S. V.; Young, N. P.; Chen, A.; Compton, R. G. Electrochemical Behavior of Gold-Silver Alloy Nanoparticles. ChemElectroChem 2016, 3, 1039-1043.

(38) Guisbiers, G.; Mendoza-Cruz, R.; Bazán-Díaz, L.; VelázquezSalazar, J. J.; Mendoza-Perez, R.; Robledo-Torres, J. A.; RodriguezLopez, J. L.; Montejano-Carrizales, J. M.; Whetten, R. L.; JoséYacamán, M. Electrum, the Gold-Silver Alloy, from the Bulk Scale to the Nanoscale: Synthesis, Properties, and Segregation Rules. ACS Nano 2016, 10, 188-198.

(39) Aly, K. M.; Esmail, E. Refractive Index of Salt Water: Effect of Temperature. Opt. Mater. 1993, 2, 195-199.

(40) Salabat, A.; Alinoori, M. Viscosity, Density, and Refractive Index of poly(vinylpyrrolidone)+1-Propanol and +2-Propanol at $298.15 \mathrm{~K}$. J. Chem. Eng. Data 2009, 54, 1073-1075.

(41) Mott, D.; Thuy, N. T. B.; Aoki, Y.; Maenosono, S. Aqueous Synthesis and Characterization of $\mathrm{Ag}$ and $\mathrm{Ag}-\mathrm{Au}$ Nanoparticles: Addressing Challenges in Size, Monodispersity and Structure. Philos. Trans. R. Soc., A 2010, 368, 4275-4292.

(42) Koczkur, K. M.; Mourdikoudis, S.; Polavarapu, L.; Skrabalak, S. E. Polyvinylpyrrolidone (PVP) in Nanoparticle Synthesis. Dalton Trans. 2015, 44, 17883-17905.

(43) Byeon, J. H.; Kim, Y.-W. An Aerosol-Seed-Assisted Hybrid Chemical Route to Synthesize Anisotropic Bimetallic Nanoparticles. Nanoscale 2012, 4, 6726-6729.

(44) Yanson, A. I.; Antonov, P. V.; Rodriguez, P.; Koper, M. T. M. Influence of the Electrolyte Concentration on the Size and Shape of Platinum Nanoparticles Synthesized by Cathodic Corrosion. Electrochim. Acta 2013, 112, 913-918.

(45) Bennett, E.; Monzó, J.; Humphrey, J.; Plana, D.; Walker, M.; McConville, C.; Fermin, D.; Yanson, A.; Rodriguez, P. A Synthetic Route for the Effective Preparation of Metal Alloy Nanoparticles and Their Use as Active Electrocatalysts. ACS Catal. 2016, 6, 1533-1539.

(46) Rodriguez, P.; Plana, D.; Fermin, D. J.; Koper, M. T. M. New Insights into the Catalytic Activity of Gold Nanoparticles for $\mathrm{CO}$ Oxidation in Electrochemical Media. J. Catal. 2014, 311, 182-189.

(47) Kromer, M. L.; Monzo, J.; Lawrence, M.; Kolodziej, A.; Gossage, Z. T.; Simpson, B. H.; Morandi, S.; Yanson, A.; Rodriguez-Lopez, J.; Rodriguez, P. High Throughput Preparation of Metal Oxide Nanocrystals by Cathodic Corrosion and Their Use as Active Photocatalysts. Langmuir 2017, 33, 13295-13302.

(48) Haccuria, E.; Ning, P.; Cao, H.; Venkatesan, P.; Jin, W.; Yang, Y.; Sun, Z. Effective Treatment for Electronic Waste-Selective Recovery of Copper by Combining Electrochemical Dissolution and Deposition. J. Cleaner Prod. 2017, 152, 150-156.

(49) Choi, S. U. S.; Eastman, J. A. In Enhancing Thermal Conductivity of Fluids with Nanoparticles, 1995 International mechanical engineering congress and exhibition, San Francisco, 1995. 